\title{
PRINCÍPIOS PARA O ENSINO DE ORALIDADE NA BASE NACIONAL COMUM CURRICULAR
}

\section{Principles for Orality Teaching in the Common National Curriculum Base}

\author{
Cristiane Malinoski Pianaro ANGELO \\ Universidade Estadual do Centro-Oeste \\ cristiane.mpa@gmail.com \\ https://orcid.org/0000-0003-2297-890X \\ Luciane Trennephol da COSTA \\ Universidade Estadual do Centro-Oeste \\ 1tcosta@unicentro.br \\ https://orcid.org/0000-0002-0223-7787 \\ Sérgio de ANDRADE \\ Universidade Estadual do Centro-Oeste \\ sergioandrade2935@gmail.com \\ https://orcid.org/0000-0002-3088-616X
}

RESUMO: Nesta pesquisa, realizou-se um estudo do componente curricular Língua Portuguesa da Base Nacional Comum Curricular (BNCC). O objetivo consistiu em levantar e discutir os conceitos e os princípios expostos no documento em relação à prática da oralidade, bem como indicar relações entre os princípios teóricos arrolados e as habilidades determinadas para a segunda etapa do Ensino Fundamental, no que se refere à oralidade. A discussão fundamentou-se teoricamente nos pressupostos do dialogismo (BAKHTIN, 2003; VOLÓCHINOV, 2013) e nas reenunciações dessa teoria na Linguística Aplicada no Brasil (ANTUNES, 2003; GERALDI, 1997; ROJO, 2009), a respeito do ensino da Língua Portuguesa. Metodologicamente, tomaram-se para a investigação os princípios da análise documental. Os resultados indicaram: a) na BNCC a oralidade envolve a produção oral e a oralização de textos; b) os princípios teóricos e as habilidades para o ensino da oralidade contemplam pressupostos da concepção dialógica da linguagem, a mobilizar os conceitos de gêneros discursivos, campos de atuação, contexto de produção, finalidade, dentre outros; c) para produção de textos orais tomam-se os mesmos princípios da produção de textos escritos, portanto, orienta-se para a consideração das etapas do processo de produção: planejamento, execução, revisão e redesign. PALAVRAS-CHAVE: Oralidade; Ensino; Língua Portuguesa; BNCC. 


\begin{abstract}
In this research, a study of the curricular component Portuguese Language of the National Common Curriculum Base (BNCC) was carried out. The objective was to raise and discuss the concepts and principles exposed in the document in relation to the practice of orality, as well as to indicate relationships between the theoretical principles listed on BNCC and the skills determined for the second stage of elementary school, with regard to orality. The discussion was theoretically based on the assumptions of dialogism (BAKHTIN, 2003; VOLÓCHINOV, 2013) and on the restatements of this theory in Applied Linguistics in Brazil (ANTUNES, 2003; GERALDI, 1997; ROJO, 2009), regarding the teaching of the Portuguese Language. Methodologically, the principles of document analysis were taken for the analysis. The results indicate: a) in BNCC, orality involves the oral production and oralization of texts; b) the theoretical principles and skills for teaching orality include assumptions of the dialogical conception of language, to mobilize the concepts of discursive genres, fields of action, production context, purpose, among others; c) for the production of oral texts, the same principles of the production of written texts are taken, therefore, it is guided by the consideration of the stages of the production process: planning, execution, revision and redesign. KEY-WORDS: Orality; Teaching; Portuguese Language; BNCC.
\end{abstract}

\title{
INTRODUÇÃO
}

Neste trabalho, apresentamos reflexões a respeito do eixo Oralidade do componente curricular de Língua Portuguesa, da Base Nacional Comum Curricular BNCC (BRASIL, 2018). A BNCC é um documento de caráter normativo que determina as aprendizagens essenciais a serem desenvolvidas progressivamente pelos alunos no decorrer das etapas da Educação Básica. O texto e os princípios da BNCC têm recebido críticas, principalmente no que se refere à sua divisão em apenas cinco áreas do conhecimento. Nesta pesquisa, nosso objetivo é analisar como está possibilitado o ensino da oralidade no componente curricular Língua Portuguesa na área de Linguagens.

A partir da homologação da BNCC, as redes de ensino de todo o país devem elaborar os currículos "com base nas aprendizagens essenciais estabelecidas na BNCC, passando, assim, do plano normativo propositivo para o plano da ação e da gestão curricular que envolve todo o conjunto de decisões e ações definidoras do currículo e de sua dinâmica" (BRASIL, 2018, p. 20). Nesse sentido, a função da BNCC é de nortear a construção das 
propostas curriculares nos sistemas educacionais, adequando as proposições da BNCC à realidade local e regional, ao contexto e às características das escolas e dos alunos.

De acordo com a BNCC (BRASIL, 2018), no componente curricular Língua Portuguesa são contempladas orientações já expostas nos Parâmetros Curriculares Nacionais - PCN (BRASIL, 1998), nos quais se compreende a linguagem como um processo de interação entre sujeitos posicionados socialmente, um processo que ocorre com finalidades específicas nas mais diversas situações e práticas sociais.

Ao se eleger para discussão o eixo Oralidade, propõe-se a levantar e a discutir os conceitos e os princípios expostos no documento em relação a essa prática, bem como indicar relações entre os princípios teóricos arrolados e as habilidades determinadas para a segunda etapa do Ensino Fundamental. A discussão fundamenta-se teoricamente nos pressupostos do dialogismo (BAKHTIN, 2003; VOLÓCHINOV, 2013) e nas reenunciações dessa teoria na Linguística Aplicada no Brasil, a considerar trabalhos como o de Antunes (2003), Rojo (2009), Costa-Hübes (2015), Rodrigues (2001), Geraldi (1997), dentre outros.

\section{CONCEPÇÕES DE LINGUAGEM E SUAS IMPLICAÇÕES NO ENSINO}

A metodologia de ensino da Língua Portuguesa na sala de aula é indissociável da concepção que o professor tem a respeito da linguagem (PERFEITO, 2010). Em vista disso, é necessário que o professor conheça as concepções de linguagem que orientam as práticas nas salas de aula e selecione qual(is) dela(s) será(ão) relevante(s) para a sua atuação pedagógica. Na Linguística Aplicada são indicadas três concepções de linguagem que influenciam as práticas pedagógicas: a linguagem como expressão do pensamento, a linguagem como instrumento de comunicação e a linguagem como forma de interação. Cada uma delas traz consequências e orientações para o trabalho com a leitura, a oralidade, a escrita e a gramática em sala de aula (PERFEITO, 2010; GERALDI, 1997).

A concepção de linguagem como expressão do pensamento fundamenta os estudos tradicionais da língua, preconizando "[...] que a expressão é produzida no interior da mente dos indivíduos. E da capacidade de o homem organizar a lógica do pensamento dependerá de sua exteriorização (do pensamento), por meio de linguagem articulada e organizada" (PERFEITO, 2010, p. 12).

Segundo Travaglia (1996), na perspectiva de que a linguagem é espelho do pensamento, compreende-se que as pessoas que não se expressam bem, não pensam. Assim, se o aluno não produz textos, escritos ou orais, adequadamente, é porque não consegue organizar seus pensamentos. Considera-se, ainda, “[...] que há regras a serem 
seguidas para a organização lógica do pensamento e, consequentemente, da linguagem" (TRAVAGLIA, 1996, p. 21).

Por isso, nessa concepção, o eixo principal do ensino é a gramática normativa no intuito de formar alunos que aprendam a organizar e a expressar seus pensamentos. A abordagem, nessa perspectiva, "evidencia o privilégio ao estudo de regras gramaticais e particulares (do padrão culto) para o bom uso e emprego da língua, com o cuidado excessivo à forma, como arte do bem escrever, redigir" (PERFEITO, 2010, p.14).

No que se refere ao ensino de leitura, a concepção de linguagem como expressão do pensamento determina que o aluno apenas extraia informações da linearidade textual, captando o pensamento do autor, por meio de exercícios ou perguntas que requisitam apenas a localização e a cópia de fragmentos. Logo, o texto apresenta, sempre, um único sentido possível, já dado, pronto e acabado. Outra prática recorrente também é a que explora excertos de obras literárias, esses considerados como modelos do "bom" uso da língua, em atividades que determinam somente a apreensão de regras gramaticais.

Rojo e Batista (2003) e Travaglia (1996) apontam que, nessa concepção, a linguagem escrita tem espaço privilegiado dentro da sala de aula, a ser utilizada como ferramenta fundamental para o desenvolvimento daquilo que é preconizado como modelo de correção. Isso leva o texto oral a não ter lugar como objeto de ensino ou, então, quando o ensino da oralidade alcança algum espaço, apregoa-se uma visão preconceituosa e distorcida da língua oral, como "o lugar do erro" e como uma modalidade oposta à escrita.

Segundo Perfeito (2010), o rompimento com a concepção de linguagem como expressão do pensamento é determinado pelos estudos saussurianos nas décadas iniciais do século XX, estudos que apontam a célebre dicotomia língua - fala, elegendo a língua (o sistema linguístico) como o principal objeto de estudo. Inaugura-se, assim, a concepção de linguagem como instrumento de comunicação vinculada ao conceito de que a língua é um código capaz de transmitir uma mensagem de um emissor a um receptor (PERFEITO, 2010).

Mesmo sendo inovadora, essa concepção ressalta o ensino pelo viés gramatical, focalizando o estudo dos fatos linguísticos por meio de exercícios estruturais para internalizar no aluno regras e hábitos linguísticos próprios da norma culta. Entretanto, a leitura e a produção textual começam a ganhar maior destaque nas aulas de Língua Portuguesa, a partir dos anos 70, ao lado dos estudos dos elementos da teoria da comunicação.

No que se refere à leitura, segundo Perfeito (2010), prevalece um olhar estruturalista, ao se considerar o ato de ler como extrair sentido da superfície do texto, 
esse concebido como receptáculo de sentidos, de verdades, que devem ser captadas pelo leitor. Desse modo, a leitura dos alunos se dá somente pela visão do autor do texto, ou seja, não lhes é permitido dialogar com o texto e produzir réplicas.

Quanto à produção textual, privilegiam-se na concepção estruturalista as tipologias tradicionais: narração, descrição, dissertação, com o intuito de formar alunos capazes de produzir redações, a partir de modelos fechados, desvinculados de uma função social.

A oralidade começa a ser considerada em uma abordagem sincrônica, mas ainda há um predomínio da língua escrita. Nesse sentido, reconhecem-se as variedades linguísticas durante o uso da língua pelo falante. Esse reconhecimento, entretanto, é apenas teórico, pois não é considerado como, de fato, possível, já que, também, não se consideram as reais situações de uso da linguagem.

$\mathrm{Na}$ concepção de linguagem como forma de interação, compreende-se que a linguagem é o espaço das relações entre sujeitos que interagem com uma finalidade específica. Para tanto, nas práticas pedagógicas, dá-se privilégio não ao estudo da palavra, das frases e dos textos isolados, mas dos enunciados e dos gêneros discursivos/textuais ${ }^{1}$ (PERFEITO, 2010).

Segundo Geraldi (2001), a concepção de linguagem em pauta sofreu influências de várias áreas de estudos, que buscaram analisar a linguagem em situação de uso, abrigadas sob um grande rótulo: linguística da enunciação (a Teoria da Enunciação de Benveniste, a Pragmática, a Semântica Argumentativa, a Análise da Conversação, a Análise do Discurso, a Linguística Textual, a Sociolinguística, a Enunciação Dialógica do Círculo de Bakhtin). Todos esses estudos buscam entender a linguagem como um trabalho coletivo, portanto em sua natureza social e histórica. Neste trabalho, destacamos a Enunciação Dialógica - ou Dialogismo - a qual põe em evidência que a realidade concreta da linguagem está na interação discursiva (BAKHTIN, 2003).

Um conceito importante que permeia essa teoria é o de gênero discursivo. Assim, os modos de dizer de cada pessoa são realizados a partir das possibilidades dadas pela língua e só podem concretizar-se por meio dos gêneros discursivos - enunciados relativamente estáveis que circulam nas diferentes áreas de atividade humana (BAKHTIN, 2003). Pode-se dizer, então, que, na concepção interacionista/dialógica de linguagem, o discurso, quando produzido, se manifesta por meio de textos e todo o texto se organiza dentro de determinado gênero.

\footnotetext{
${ }^{1}$ As discussões teóricas sobre as definições de gêneros do discurso, gênero discursivo, gênero do texto e gênero textual não são de interesse aqui. Assim, utiliza-se a nomenclatura gênero discursivo/textual para resolver essa diferença, que não é substancial à pesquisa descrita. 
Em termos pedagógicos, os gêneros discursivos, segundo os Parâmetros Curriculares Nacionais - PCN (BRASIL, 1998), tornam-se objeto de ensino (responsáveis pela articulação/progressão dos programas curriculares). Assim, na situação de leitura, a concepção interacionista leva em conta três elementos que instituem o processo interativo, realizado por meio de um gênero: o autor que produz o texto e suas intencionalidades, o material linguístico-textual e o leitor com seus conhecimentos prévios (KOCH; ELIAS, 2006). Há, então, um diálogo entre o leitor, o texto e o autor de modo que todos fornecem informações para que ocorra a leitura, a produção de sentidos.

Costa-Hübes (2015) acrescenta nessa concepção os aspectos sociais e discursivos inerentes aos enunciados, considerando que os textos são sempre originados como respostas a outros enunciados, são tomados pelo leitor de forma ativa/responsiva, a gerar réplicas (ROJO, 2009) e reenunciar os enunciados já ditos.

Ao se considerar as condições de produção textual, a prática de escrita adquire um status de prática interlocutiva, que possibilita relações entre sujeitos situados socialmente - sujeitos ativos, capazes de se posicionar, emitir opiniões sobre fatos do mundo, dialogar com o outro. Em uma visão interacionista, Geraldi (1997) aponta que, para produzir textos, é preciso que:

a) se tenha o que dizer;

b) se tenha uma razão para dizer o que se tem a dizer;

c) se tenha para quem dizer o que se tem a dizer;

d) o locutor se constitua como tal, enquanto sujeito que diz o que diz para quem diz (ou, na imagem wittgensteiniana, seja um jogador no jogo);

e) se escolham as estratégias para realizar (a), (b), (c) e (d) (GERALDI, 1997, p. 136).

A partir dessas condições, a escrita constitui-se como um espaço de interação social que depende de um gênero discursivo e de uma finalidade, de um locutor e um interlocutor que compartilham de conhecimentos afins e se posicionam como sujeitos. Ainda no que se refere à escrita, há uma ênfase nas etapas da produção escrita: planejamento, execução, revisão e reescrita (MENEGASSI, 2016).

No planejamento, o professor propicia situações interativas reais que embasam sobre aquilo (assunto e argumentos) que se pretende desenvolver, no intuito de que a segunda etapa, a execução, possa se dar com conteúdo bem estruturado. A revisão, por sua vez, é a oportunidade de interação entre autor e leitor, seja este último o professor, um colega ou o próprio autor do texto, oportunizando um diálogo com vistas à ampliação do conteúdo e da forma de exposição. A revisão tem por finalidade apontar elementos a Revista X, v. 16, n. 6, p. 1476-1492, 2021. 
serem modificados na última etapa, a reescrita, que é um momento de reflexão sobre a língua e o discurso (MENEGASSI, 2016).

Sob a ótica da concepção interacionista, há uma mudança na perspectiva dos estudos gramaticais, ao se dar ênfase à análise linguística, conceituada como um processo reflexivo (epilinguístico) realizado pelos alunos, em relação aos recursos textuais, lexicais e gramaticais presentes nos gêneros discursivos, veiculados no processo de oralidade, leitura, de produção e de reescrita (PERFEITO, 2010).

Conforme apontam as Diretrizes Curriculares de Língua Portuguesa do Estado do Paraná - DCE (2008), as práticas pedagógicas devem pautar-se "na interlocução, em atividades planejadas que possibilitem ao aluno a (...) reflexão sobre o uso da linguagem em diferentes situações e contextos" (PARANÁ, 2008, p. 24). Essa reflexão, por sua vez, possibilitará ao aluno a consciência de que a leitura, a oralidade e a produção escrita são práticas sociais que se realizam por meio da linguagem, em forma de textos, pertencentes a determinado gênero.

Com base nos fundamentos da concepção de linguagem como interação, são evidenciados muitos avanços no tratamento do ensino da língua oral, tanto nos estudos realizados por diferentes pesquisadores (GERALDI, 1996; CASTILHO, 2011; MARCUSCHI, 2007; DOLZ; SCHNEUWLY, 2004; dentre outros), como nos documentos oficiais, como os PCN (Brasil, 1998). Segundo Marcuschi e Dionísio:

Em si não haveria necessidade de justificar o trabalho com a oralidade em sala de aula, pois parece natural que isso deva ocorrer. O espantoso é que se tenha demorado tanto para chegar a esse reconhecimento. O que deveria ser explicado é o escândalo da ausência, e não a estranheza da presença do trabalho com a oralidade na sala de aula, ao lado do trabalho com a escrita (MARCUSCHI; DIONÍSIO; 2007, p. 08).

Na perspectiva dos PCN, a oralidade ganha espaço em sala de aula, a ser trabalhada em práticas de escuta de textos orais e práticas de produção de textos orais, visando a que o aluno aprimore as possibilidades do domínio discursivo da língua oral, ou seja, do domínio dos gêneros discursivos/textuais orais que permeiam os campos de atuação dos sujeitos em sociedade. Assim, para o documento:

Ensinar língua oral deve significar para a escola possibilitar acesso a usos da linguagem mais formalizados e convencionais, que exijam controle mais consciente e voluntário da enunciação, tendo em vista a importância que o domínio da palavra pública tem no exercício da cidadania. Ensinar língua oral não significa trabalhar a capacidade de falar em geral. Significa desenvolver o domínio dos gêneros que 
apóiam a aprendizagem escolar de Língua Portuguesa e de outras áreas e, também, os gêneros da vida pública no sentido mais amplo do termo (BRASIL, 1998, p. 67).

De forma coerente com a concepção de linguagem como forma de interação, a noção de gêneros discursivos/textuais, destacada nos PCN, vem impulsionando nas últimas décadas um novo olhar para o ensino da oralidade em sala de aula. De acordo com Bakhtin, é por meio dos gêneros discursivos - formas de enunciados, concretos e únicos, relativamente estáveis, orais, escritos e multimodais - que nos inserimos e interagimos socialmente. Sendo assim, tomar essa noção como orientadora das práticas de ensino significa propiciar ao aluno instrumentos que podem ser usados de forma relevante em diversos contextos sociais de uso da linguagem. Nesse sentido, podemos afirmar que os gêneros orais tornam o ensino da oralidade significativo para o aluno, oferecendo-lhe instrumentos linguísticos que podem ser usados de forma relevante em vários contextos sociais de linguagem.

\section{A ORALIDADE NA BNCC}

A metodologia desta pesquisa constitui-se em uma análise documental. Para tanto, procedemos à leitura da BNCC perscrutando os princípios e as habilidades que envolvem a oralidade e a oralização para a segunda etapa do Ensino Fundamental. Concomitantemente, analisa-se a prática preceptuada na base e os princípios teóricos e conceptuais que subjazem a tal prática.

A BNCC fundamenta-se "na perspectiva enunciativo-discursiva de linguagem" (BRASIL, 2018, p. 65) e assume o texto como unidade de trabalho, a orientar encaminhamentos que levam em conta essa unidade a partir de seu pertencimento a um gênero discursivo que circula em diferentes esferas sociais de uso da linguagem.

Trabalhar o texto, nessa perspectiva, tem como intuito desenvolver habilidades de oralidade, de leitura e de escrita que favoreçam ao aluno ampliar as condições de participação em práticas de diferentes campos de atuação ou atividades humanas, sendo esses campos: 
Figura 1: Campos de atuação nos níveis de ensino.

\begin{tabular}{|l|l|}
\hline Anos iniciais & Anos finais \\
\hline Campo da vida cotidiana & \\
\hline Campo artístico-literário & Campo artístico-literário \\
\hline Campo das práticas de estudo e pesquisa & Campo das práticas de estudo e pesquisa \\
\hline Campo da vida pública & Campo jornalístico-midiático \\
\cline { 2 - 2 } & Camoo de atuacăo na vida oública \\
\hline
\end{tabular}

Fonte: (BRASIL, 2018, p. 84).

Conforme se aponta no documento, a escolha desses campos se deu por entender que estes são subsídios para a organização de um trabalho que vincule as aprendizagens aos usos sociais da linguagem, a criar condições para:

[...] uma formação para a atuação em atividades do dia a dia, no espaço familiar e escolar, uma formação que contempla a produção do conhecimento e a pesquisa; o exercício da cidadania, que envolve, por exemplo, a condição de se inteirar dos fatos do mundo e opinar sobre eles, de poder propor pautas de discussão e soluções de problemas, como forma de vislumbrar formas de atuação na vida pública; uma formação estética, vinculada à experiência de leitura e escrita do texto literário e à compreensão e produção de textos artísticos multissemióticos (BRASIL, 2018, p. 84).

A área de Língua Portuguesa na BNCC leva em conta esses campos e encontrase organizada em torno de quatro grandes eixos: "oralidade, leitura/escuta, produção (escrita e multissemiótica) e análise linguística/semiótica (que envolve conhecimentos linguísticos, textuais, discursivos e sobre modos de organização e os elementos de outras semioses)" (BRASIL, 2018, p. 71).

A oralidade na BNCC abrange:

As práticas de linguagem que ocorrem em situação oral com ou sem contato face a face, como aula dialogada, webconferência, mensagem gravada, spot de campanha, jingle, seminário, debate, programa de rádio, entrevista, declamação de poemas (com ou sem efeitos sonoros), peça teatral, apresentação de cantigas e canções, playlist comentada de músicas, vlog de game, contação de histórias, diferentes tipos de podcasts e vídeos, dentre outras. Envolve também a oralização de textos em situações socialmente significativas e interações e discussões envolvendo temáticas e outras dimensões linguísticas do trabalho nos diferentes campos de atuação (BRASIL, 2018, p.78-79). 
Pode-se observar que o documento propõe gêneros orais ainda pouco utilizados na escola, como, por exemplo, o vlog, que é um tipo de blog em que os conteúdos predominantes são os vídeos; e o podcast, um material que circula na forma de áudio, muito semelhante a um programa de rádio. Se por um lado a sugestão desses gêneros aproxima muito mais os alunos dos usos atuais e sociais da linguagem, por outro exige do professor um preparo para trabalhar esses enunciados, de forma a aproximar escola e sociedade e a desenvolver nos alunos um uso mais competente, criativo e crítico da língua oral.

$\mathrm{Na}$ Base, o eixo oralidade compreende tanto as práticas de linguagem que ocorrem em situação oral com ou sem contato face a face, como também a oralização de textos "[...] em situações socialmente significativas e interações e discussões envolvendo temáticas e outras dimensões linguísticas do trabalho nos diferentes campos de atuação" (BRASIL, 2018, p. 78-79). Segundo Marcuschi (2007), muitos docentes confundem oralidade e oralização, a tratá-las como similares, o que causa embaraços em um trabalho mais sistemático com tais práticas.

O autor afirma que "não se pode confundir oralização com oralidade", ao trazer, como exemplo, as notícias nas rádios e nos telejornais, que "são uma escrita oralizada, o que não equivale, em hipótese alguma, à língua falada como tal. Também a letra de música que geralmente só nos chega pelo canto, mas que não se chamaria legitimamente de língua falada" (MARCUSCHI, 2007. p. 71). Assim, em sala de aula é necessário se ter claro o que é oralidade e o que é oralização. Veja-se, como exemplo, um trabalho com um jogral, este por vezes caracteriza-se uma oralização, o que não pode ser confundido com oralidade, porque neste caso o aluno apenas lê o que está escrito, sem efetivar um trabalho de produção oral.

Percebe-se, assim, que a BNCC, embora sem esclarecer o que se entende por essas práticas, concede um espaço relevante tanto para a oralidade como para a oralização de textos, a garantir que as duas sejam trabalhadas nas aulas de Língua Portuguesa. Citamse, como exemplos, as habilidades, para o $6^{\circ}$ ao $9^{\circ}$ ano: "Desenvolver estratégias de planejamento, elaboração, revisão, edição, reescrita/ redesign [...] e avaliação de textos orais, áudio e/ou vídeo [...]” (BRASIL, 2018, p. 143); "Ler em voz alta textos literários diversos [...] bem como leituras orais capituladas (compartilhadas ou não com o professor) de livros de maior extensão [...]" (BRASIL, 2018, p. 159).

A BNCC apresenta alguns princípios gerais para o tratamento da oralidade, os quais abrangem: a) o levantamento e a reflexão acerca das condições de produção dos textos orais; b) a compreensão de textos orais; c) a produção de textos orais; d) a discussão 
dos efeitos de sentidos de recursos linguísticos e multissemióticos em textos orais; d) a relação entre fala e escrita.

Verifica-se que o primeiro princípio enuncia os princípios da concepção dialógica de linguagem, ao orientar que o texto seja analisado considerando a sua dimensão extraverbal ou social. Conforme Rodrigues (2001, p. 20), "não se pode compreender o enunciado [orais, escritos ou multimodais] sem correlacioná-lo com a sua situação social, pois o discurso, como fenômeno da comunicação social, é determinado pelas relações que o suscitaram". Desse modo, a BNCC, ao sugerir o levantamento e a reflexão das condições de produção dos textos orais, favorece pensar o texto oral como lugar de manifestação viva da linguagem.

Mas o que envolve o estudo das condições de produção ou a dimensão extraverbal do texto oral? Costa-Hübes (2015) aponta alguns questionamentos que podem conduzir o professor no trabalho com os elementos extraverbais: Onde é produzido? Qual é a esfera social de produção? Quando é produzido? Com que finalidade foi produzido? Quem produziu? Qual é o papel social do autor? Para quem foi produzido? Esse princípio pode ser percebido na seguinte habilidade:

Produzir notícias para rádios, TV ou vídeos, podcasts noticiosos e de opinião, entrevistas, comentários, vlogs, jornais radiofônicos e televisivos, dentre outros possíveis, relativos a fato e temas de interesse pessoal, local ou global e textos orais de apreciação e opinião - podcasts e vlogs noticiosos, culturais e de opinião, orientando-se por roteiro ou texto, considerando o contexto de produção e demonstrando domínio dos gêneros (BRASIL, 2018, p. 159).

A BNCC, ainda no primeiro princípio, determina "refletir sobre diferentes contextos e situações sociais em que se produzem textos orais e sobre as diferenças em termos formais, estilísticos e linguísticos que esses contextos determinam, incluindo-se aí a multimodalidade e a multissemiose" (BRASIL, 2018, p. 79, grifos nossos). Há nessa citação a orientação para que se observe a dimensão verbal do enunciado oral - termos formais, estilísticos e linguísticos, em sua relação com a dimensão extraverbal ou social. Desse modo, os recursos da língua são vistos como indissociáveis do horizonte social do texto; por exemplo, em um seminário escolar, são comuns as saudações de abertura, o uso de exemplos, a ligação das partes dos assuntos tratados por meio de organizadores textuais (o primeiro, o segundo, a seguir, etc); o uso de expressões que explicitem quais são as informações principais e quais são as secundárias, com o intuito de propiciar ao ouvinte uma melhor orientação e compreensão quanto ao conteúdo exposto no seminário. 
Assim, todos esses elementos são apresentados em função da finalidade do gênero, da posição dos interlocutores, da situação comunicativa.

No que se refere à compreensão de textos orais, o documento orienta:

Proceder a uma escuta ativa, voltada para questões relativas ao contexto de produção dos textos, para o conteúdo em questão, para a observação de estratégias discursivas e dos recursos linguísticos e multissemióticos mobilizados, bem como dos elementos paralinguísticos e cinésicos (BRASIL, 2018, p. 79).

Na BNCC, a escuta abarca a compreensão do contexto de produção dos textos, isto é, a situação social que envolve o texto oral, a apreensão das informações contidas no texto, o conteúdo, como também a observação das estratégias discursivas usadas pelo autor (como, por exemplo, as pausas, os sequenciadores e as repetições), os recursos paralinguísticos (como a altura da voz) e cinésicos (por exemplo, movimentos do corpo como gestos, postura, expressão facial, olhar e riso). A seguinte habilidade ressalta esses aspectos: "Analisar, em gêneros orais que envolvam argumentação, os efeitos de sentido de elementos típicos da modalidade falada, como a pausa, a entonação, o ritmo, a gestualidade e expressão facial, as hesitações etc." (BRASIL, 2018, p. 143).

Verifica-se que permeiam o documento habilidades que colocam o ouvinte na posição sujeito ativo, que não apenas apreende o que é exposto pelo outro, mas que é capaz de dialogar, contrapor-se, contestar, concordar, em um efetivo diálogo com o produtor do texto. Por exemplo: "Identificar e analisar posicionamentos defendidos e refutados na escuta de interações polêmicas em entrevistas, discussões e debates (televisivo, em sala de aula, em redes sociais etc.), entre outros, e se posicionar frente a eles" (BRASIL, 2018, p. 141); habilidade que está relacionada aos fundamentos dialógicos que destacam que o enunciado, como unidade real de comunicação, está disposto para a compreensão e a resposta do outro. Dessa forma:

O ouvinte que recebe e compreende a significação de um discurso adota para com este discurso uma atitude responsiva ativa: ele concorda ou discorda, completa, adapta [...]. A compreensão de uma fala, de um enunciado é sempre acompanhada de uma atitude responsiva ativa (VOLOCHINOV, 2013, p. 271).

Outro princípio da BNCC se refere à produção de textos orais, orientandose a "Produzir textos pertencentes a gêneros orais diversos, considerando-se aspectos relativos ao planejamento, à produção, ao redesign, à avaliação das práticas realizadas 
em situações de interação social específicas" (BRASIL, 2018, p. 79). Pode-se observar que a BNCC toma para a produção de textos orais os mesmos pressupostos da produção de textos escritos, ponderando, portanto, a produção oral como um trabalho que envolve o planejar, o escrever (a produção efetiva do texto), o reelaborar (denominada redesign na BNCC) e o avaliar a prática. Essa orientação aparece explicitamente no documento: “*Considerar todas as habilidades dos eixos leitura e produção que se referem a textos ou produções orais, em áudio ou vídeo" (BRASIL, 2018, p. 140). As seguintes habilidades contemplam a produção do texto oral como um trabalho que envolve as condições de produção e as etapas do processo de produção:

Produzir notícias para rádios, TV ou vídeos, podcasts noticiosos e de opinião, entrevistas, comentários, vlogs, jornais radiofônicos e televisivos, dentre outros possíveis, relativos a fato e temas de interesse pessoal, local ou global e textos orais de apreciação e opinião - podcasts e vlogs noticiosos, culturais e de opinião, orientando-se por roteiro ou texto, considerando o contexto de produção e demonstrando domínio dos gêneros". (BRASIL, 2018, p. 141) "Produzir, revisar e editar textos voltados para a divulgação do conhecimento e de dados e resultados de pesquisas, tais como [...] podcast ou vlog científico [...] considerando o contexto de produção e as regularidades dos gêneros em termos de suas construções composicionais e estilos (BRASIL, 2018, p. 151).

Outro princípio da oralidade se refere à discussão dos efeitos de sentidos de recursos linguísticos e multissemióticos em textos orais: "Identificar e analisar efeitos de sentido decorrentes de escolhas de volume, timbre, intensidade, pausas, ritmo, efeitos sonoros, sincronização, expressividade, gestualidade etc. e produzir textos levando em conta efeitos possíveis". (BRASIL, 2018, p. 79). O trabalho com a oralidade e a oralização deve estar atrelado à reflexão acerca dos elementos paralinguísticos e cinésicos, visto que uma leitura bem-feita de um jogral ou poema ou uma produção oral como em uma apresentação de seminário escolar, requerem o uso adequado do volume, das pausas, das expressões faciais e da gestualidade. Sendo assim, é importante que o aluno ouça e reflita com o professor textos orais, para que ele aprenda a fazer uso adequado desses textos orais, em situações sociais que requeiram esses usos.

Ainda quanto ao tratamento das práticas orais, a BNCC orienta para os estudos da relação entre fala e escrita, a levar em conta o modo como essas modalidades se articulam em diferentes gêneros, as semelhanças e as diferenças entre os modos de fala e de registro do escrito, como também os elementos discursivos, composicionais e linguísticos de cada modalidade. Trata-se, assim, de um trabalho que visa à compreensão de como 
essas modalidades da linguagem são operacionalizadas, quais são as suas características constitutivas, a partir do estudo de diferentes práticas e gêneros, por exemplo, como uma notícia é veiculada em um jornal escrito e como é veiculada em um telejornal, evitandose marcar a superioridade da escrita, tão evidenciada na sociedade grafocêntrica.

Segundo Antunes (2003), essa supremacia da escrita sobre a fala nada mais é que uma ótica equivocada, pois se pensa que a fala é o lugar propício para a violação das regras da gramática. Essa visão ingênua de superioridade da escrita sobre a fala corresponde aos ensinos tradicionalistas, que detinham a gramática como única ferramenta de ensino. De acordo com a autora:

Com o devido cuidado para que não se crie ideia falseada de que a fala se opõe à escrita, será interessante que o professor saiba ressaltar os pontos formais e funcionais em que os textos orais e os textos escritos são diferentes. Como se sabe, as modalidades orais e escritas da língua guardam similaridades e apresentam diferenças. $\mathrm{O}$ confronto entre uma e outra - desde que se considerem os mesmos níveis de registro (fala formal e escrita formal, por exemplo) - pode ser bastante produtivo para compreensão daquelas similaridades e diferenças e para entendimento das mútuas influências de uma sobre a outra. (ANTUNES, 2010, p. 101).

Ponderamos também o trabalho com as variações linguísticas, estas que necessitam ser abordadas de forma atenta pelo educador para inibir o preconceito linguístico. É pertinente que o educador trabalhe as questões de variações de fala e escrita já que esse pode ser um meio para ressaltar o respeito aos falares de cada um (BRASIL, 2018).

Com atenção ao despertar para o senso de criticidade, ensinam-se os alunos a respeitar os diferentes usos da fala dentro e fora da sala de aula, já que o preconceito não está somente ligado às diferenças regionais, mas se relaciona a todo juízo de valor negativo de reprovação, de repulsa ou mesmo de desrespeito às variedades linguísticas de menor prestígio social. Normalmente, o julgar recai às classes menos favorecidas, ou seja, as que não tiveram uma escolarização capaz de ensiná-los e adequá-los a um padrão educacional (BAGNO, 2009).

As relações entre fala e escrita e o reconhecimento das variedades linguísticas aparecem na BNCC nas seguintes habilidades: "Reconhecer as variedades da língua falada, o conceito de norma-padrão e o de preconceito linguístico"; "Fazer uso consciente e reflexivo de regras e normas da norma-padrão em situações de fala e escrita nas quais ela deve ser usada" (BRASIL, 2018, p. 159).

As questões relacionadas às variedades linguísticas e ao preconceito linguístico também podem ser abordadas pelo viés da valoração (VOLOCHINOV, 2013; BAKHTIN, 
2003). Isso porque as palavras são sempre carregadas de valorações, constituem signos ideológicos. Dessa forma, é possível discutir com o aluno que valores sociais carregam determinadas formas/variantes linguísticas em suas relações com os contextos de usos e os falantes; por que algumas formas são desprestigiadas e outras não; que efeitos as valorações sobre aspectos linguísticos exercem na vida das pessoas. As noções de enunciado, gênero discursivo/textual, réplica, valoração, a partir dos estudos do dialogismo, que perpassam a BNCC, favorecem um trabalho que contempla a oralidade não apenas em relação às diferenças com a escrita, mas como uma prática social, concreta, situada, ideológica e valorada.

\section{CONSIDERAÇÕES FINAIS}

Neste trabalho, buscou-se levantar e discutir os conceitos e os princípios expostos na $\mathrm{BCCC}$ em relação à prática oral, bem como indicar relações entre os princípios teóricos arrolados e as habilidades determinadas para a segunda etapa do Ensino Fundamental. Constatou-se que na BNCC concede-se um espaço relevante tanto para a oralidade como para a atividade de oralização de textos. Os princípios teóricos e as habilidades para o trabalho com essas práticas contemplam pressupostos da concepção dialógica da linguagem, a mobilizar os conceitos de gêneros discursivos, campos de atuação, contexto de produção, finalidade, dentre outros. No que se refere à escuta de textos orais, há indicações para o estudo da situação social que envolve o texto oral, bem como das estratégias discursivas usadas pelo autor (pausas, os sequenciadores e as repetições), os recursos paralinguísticos (como a altura da voz) e cinésicos (movimentos do corpo como gestos, postura, expressão facial, olhar e riso). Para produção de textos orais tomam-se os mesmos princípios da produção de textos escritos, portanto, orientase para a consideração das etapas do processo de produção: planejamento, execução, revisão e redesign. Assim, considera-se a produção oral como um trabalho processual.

No atual contexto educacional do século XX, maximizado pelo ensino remoto possível de ser praticado na pandemia de COVID-19, com a produção e circulação de textos multimodais e multissemióticos, o ensino da oralidade e da oralização torna-se ainda mais relevante. É o ensino com base nas condições sociais de produção dos textos, a serem produzidos e consumidos, que promoverá a inserção crítica e capacitada dos alunos nos novos gêneros digitais presentes.

Como mostrado nesta pesquisa, o atual documento que orienta o processo de ensino aprendizagem da língua portuguesa nos anos finais do ensino fundamental possibilita o ensino significativo e calcado em reais condições de produção de textos escritos e orais. 
$\mathrm{O}$ ensino da oralidade e da oralização estão presentes na BNCC e fundamentados em princípios teóricos de uma concepção dialógica de linguagem. Fazem-se necessárias agora pesquisas que investiguem caminhos e abordagens para o ensino desse componente, a oralidade, durante muito tempo silenciada no processo de ensino aprendizagem da língua portuguesa.

\section{REFERÊNCIAS}

ANTUNES, I. Aula de português: encontro \& interação. São Paulo: Parábola Editorial, 2003.

Análise de textos: fundamentos e práticas. São Paulo: Parábola Editorial, 2010.

BAGNO, M. Preconceito linguístico: o que é, como se faz. 51.ed. São Paulo: Loyola, 2009.

BAKHTIN, Mikhail. Gêneros do discurso. In: Estética da criação verbal. Introdução e tradução do russo por Paulo Bezerra; prefácio à edição francesa Tzvetan Todorov. São Paulo: Martins Fontes, 2003.

BRASIL. Ministério da Educação. Base Nacional Comum Curricular. Brasília: MEC, 2018. http://basenacionalcomum.mec.gov.br/images/BNCC_EI_EF_110518_ versaofinal_site.pdf. Acesso em: 13 de jan. 2021

COSTA-HÜBES, T. da C. (Org.). Atividades de Leitura e de Análise Linguística: $5^{\circ}$ ano Cascavel-PR: ASSOESTE, 2015. Caderno Pedagógico. 01.

CASTILHO, A. A língua falada no ensino de português. 7.ed. São Paulo, SP: Contexto, 2011.

GERALDI, J. W. O texto na sala de aula. São Paulo/SP: Editora Ática, 2001.

Portos de passagem. São Paulo: Martins Fontes, 1997.

KOCH, I. V.; ELIAS, V. M.. Ler e compreender: os sentidos do texto. São Paulo: Contexto, 2006.

MARCUSCHI, L. A. A oralidade no contexto dos usos lingüísticos: caracterizando a fala. In: MARCUSCHI, L. A.; DIONISIO, A. P. Fala e escrita. Belo Horizonte: Autêntica, 2007. 
MARCUSCHI, L. A.; DIONÍSIO, A. P. Fala e escrita. Belo Horizonte: Autêntica, 2007.

MENEGASSI, R. J. A escrita como trabalho na sala de aula. In: JORDÃO, C. M. A Linguística Aplicada no Brasil: rumos e passagens. Campinas: Pontes, 2016.

PARANÁ. Secretaria de Estado da Educação; Superintendência da Educação. Diretrizes Curriculares da Educação Básica: Língua Portuguesa. Curitiba: SEED/DEE, 2008.

PERFEITO, A. M. Concepções de linguagem, teorias subjacentes e ensino de língua portuguesa. In: RITTER, L. C. R.; SANTOS, A. R. (Orgs.). Concepções de linguagem e ensino de língua portuguesa. Coleção Formação de Professores EAD Maringá: Eduem, 2010 .

RODRIGUES. R. H. A Constituição e Funcionamento do Gênero Jornalístico Artigo: Cronotopo e Dialogismo. Tese (Doutorado em Linguística Aplicada e Estudos da Linguagem - LAEL - PUCSP). São Paulo: PUCSP, 2001.

ROJO, R.; BATISTA, A. A. G. (Orgs.). O livro didático de língua portuguesa no ensino fundamental: letramento escolar e cultura da escrita. Campinas: Mercado de Letras, 2003.

ROJO, R.. Letramentos múltiplos, escola e inclusão social. São Paulo: Parábola Editorial, 2009.

SCHNEUWLY, B; DOLZ, J. Gêneros Orais e escritos na escola. Trad. e org. ROJO, Roxane; CORDEIRO, Glaís S. São Paulo: Mercado das Letras, 2004.

TRAVAGLIA, L. C. Gramática e interação: uma proposta para o ensino de gramática no $1^{\circ}$ e $2^{\circ}$ graus. São Paulo: Cortez, 1996.

VOLOCHINOV, V. N. Marxismo e filosofia da linguagem. 16. ed. São Paulo: Hucitec, 2013[1929].

Recebido em: 30 jul. 2021.

Aceito em: 20 set. 2021. 